\title{
The Monte Alen-Monts De Cristal Landscape
}

\section{Chrislain Eric Kenfack}

\section{Introduction}

The Monte Alén-Monts de Cristal (MA-MC) landscape covers $26747 \mathrm{~km}^{2}$, nearly half of which is in the northwest of Gabon with the remainder in the southeast of Equatorial Guinea. It is made up of three ecoregions: Atlantic Congolese forest ecoregion, the central West equatorial coastal ecoregion and the southwest equatorial coastal ecoregion.

The landscape occupies a plateau and mountain ranges. Annual rainfall ranges from $2000 \mathrm{~mm}$ in the east to $2800 \mathrm{~mm}$ in the west. There is a period of drought between July and September that is greatly softened by the presence of low cloud cover over a substantial area.

Overall, the forest concessions cover $65 \%$ of the area, the protected areas cover 18\%, with $27 \%$ of these protected areas in Equatorial Guinea; only 3\% of the area is used for agriculture. On the Gabonese side, two hydroelectric dams have been built in the Mbé Valley to supply the capital city, Libreville (Devers and Vande weghe 2007).

\section{Populations}

The two main ethnic groups in the landscape are the Fang, who live primarily in mountainous areas, and the Ndowe, in the coastal basin in Equatorial Guinea. The Beyele pygmies, who used to live in the Altos de Nsork area, moved to southern Cameroon and other areas of the forest two decades ago. According to the most recent available statistics (2006), the average population density is 16-18 inhabitants/ $\mathrm{km}^{2}$ on the Equatoguinean side and 0.6 inhabitants $/ \mathrm{km}^{2}$ on the Gabonese side.

\section{Forest coverage}

Forest covers $26101 \mathrm{~km}^{2}$ of the MA-MC landscape (de Wasseige and Devers 2009), in which vegetation is very diverse and rich. The main types of landscape are humid lowland forest, degraded humid lowland forest, mountainous forest, degraded mountainous forest, secondary forest and savannah, as well as small extension of abandoned gaboon forest.

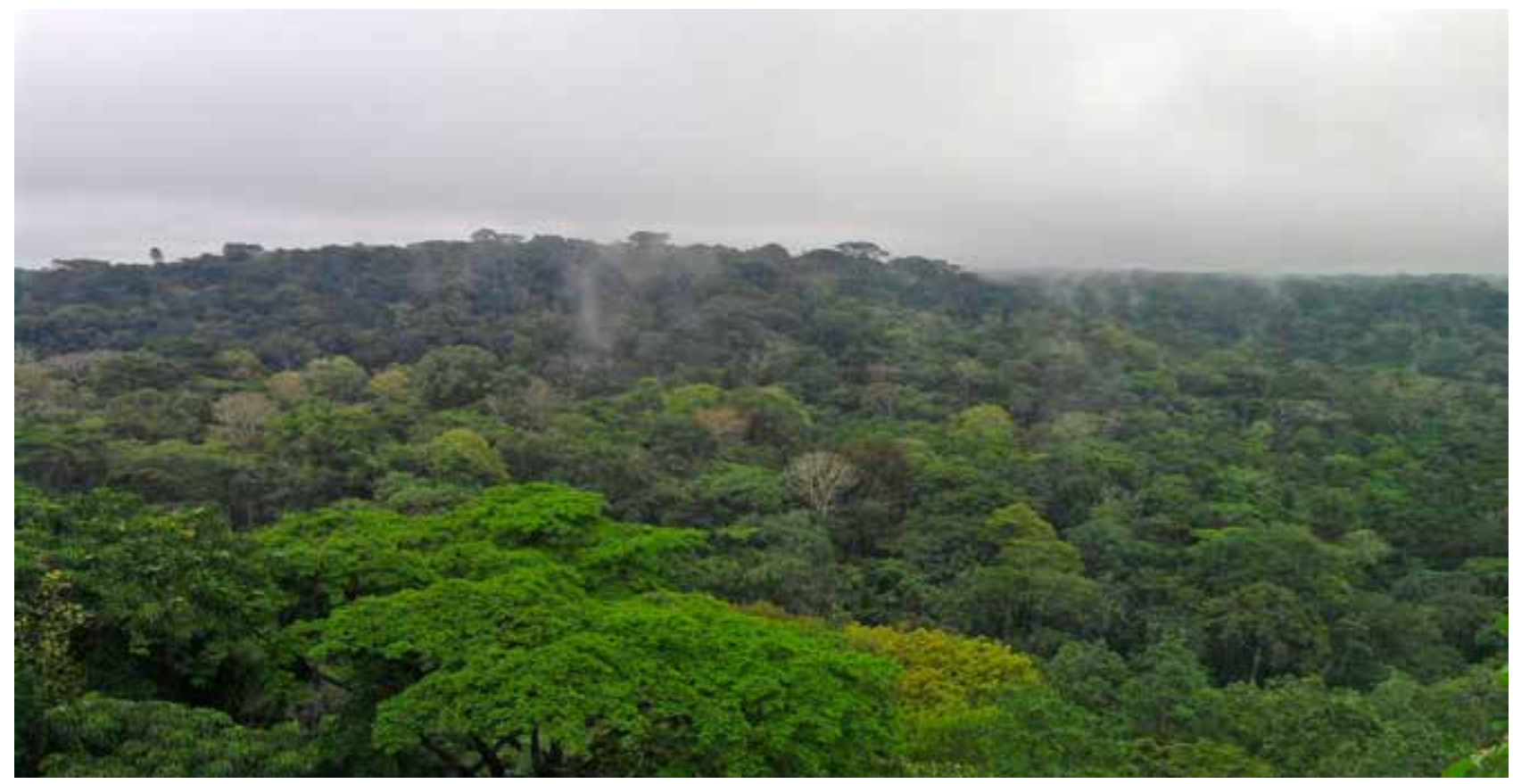




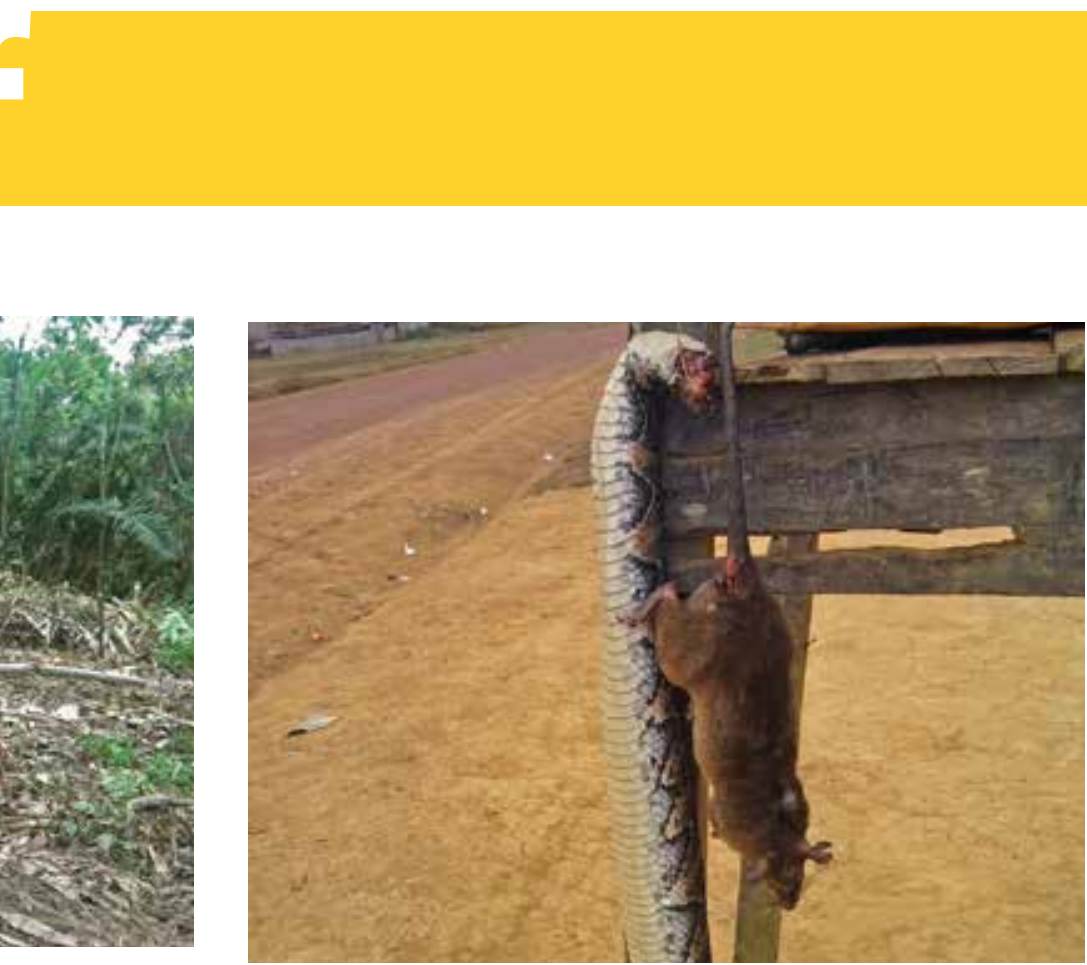

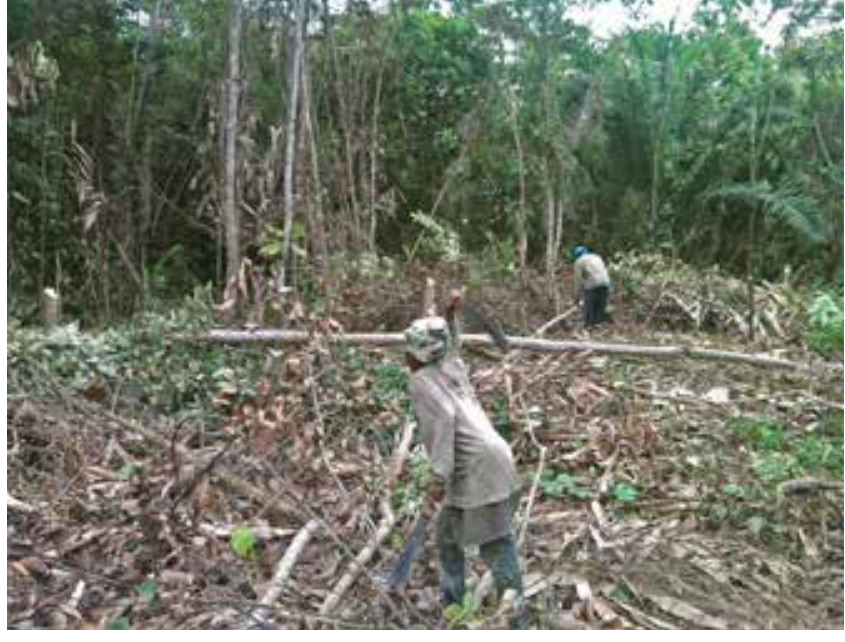

Preparation of the farm for the household farming

\section{Deforestation}

Deforestation is a major threat to the landscape. Between 1990 and 2000, $128 \mathrm{~km}^{2}$ of forest, or $0.49 \%$ of the total, was lost (de Wasseige and Devers 2009). Although some of this deforestation is attributable to agricultural activities, mainly subsistence agriculture, the main driver is industrial exploitation of the timber by forest companies and small-scale exploitation of wood for handicrafts and energy needs.

\section{Biodiversity}

The MA-MC landscape is characterised by exceptionally rich biodiversity, featuring:

- $\quad$ at least 35 species of mammals (about 10 of which are primates), including Gorilla gorilla (western gorilla), Pan troglodytes (common chimpanzee), Colobus satanas (black coolubus), Mandrillus sphinx (mandrill), Cercocebus torquatus (collared mangabey), Panthera pardus (leopard), Felis aurata (African golden cat) and Loxodonta Africana (African bush elepant);

- at least 246 species of birds, including Phylloscopus budongoensis (Uganda Woodland-Warbler), Batis minima (Gabon Batis) , Batis poensis (Fernando Po Batis) and Malimbus racheliae (Rachel's Malimbe);

- $\quad$ at least 25 species of reptiles;

- $\quad$ at least 27 species of amphibians, including Petropedetes palmipes and Leptodactylodon stevarti; and

- numerous endemic butterflies, including Cymothoe haimodia (Nymphalidae) (Haimodia Red Glider), Abantis eltringhami (Hesperiidae) and Saturniidae (Devers and Vande weghe 2007).

\section{Threats to biodiversity conservation}

The main threats to biodiversity in the landscape are:
Bushmeat for sale in a village

- illegal hunting and the commercialisation of bushmeat, driven by increased purchasing power in Equatorial Guinea;

- $\quad$ sale of elephant ivory on the Gabonese side;

- industrial and non-sustainable exploitation of wood, attributable to poor compliance with conservation laws and regulations;

- $\quad$ uncertain financial resources and lack of capacity among officials responsible for managing the landscape;

- agricultural expansion;

- $\quad$ artisanal and industrial mining; and

- unsustainable extraction of non-timber forest products for consumption and sale.

\section{Land administration and land use}

The following land use types are present in the landscape.

Three national parks

- Monte Alén National Park in Equatorial Guinea, which spans 200000 ha, is one of the most important reservoirs for biodiversity in the Congo Basin because it has a high level of plant diversity and endemism and one of Africa's highest encounter rates for forest elephants.

- $\quad$ Altos de Nsork National Park in Equatorial Guinea, which spans 70000 ha and whose main ecosystem high elevation humid forest, is home to a population of lowland gorillas under threat of extinction as well as emblematic animals such as chimpanzees, mandrills, colobuses, leopards and elephants.

- Monts de Cristal National Park in Gabon, which spans 120000 ha is largely inaccessible to humans because of its dense river forests, widely variable topography (elevation ranges from 200 to 900 metres) and constant mists and cloud cover. Consequently, it is almost virgin territory. 
Three reserves

- Monts de Cristal military Reserve, established on the Gabonese side with the help of the Wildlife Conservation Society (WCS);

- Piedra Nzas National Monument in Equatorial Guinea, spanning 19000 ha; and

- $\quad$ Rio Muni Natural Reserve in Equatorial Guinea, spanning 70000 ha (Devers and Vande weghe 2007).

Furthermore, the land use plan recognises six delimited macrozones:

- three community-based natural resource management areas, namely the Kougouleu-Medouneu-Mbéarea, Equatorial Guinea National Forest and the Abanga River area; and

- Three areas for natural resource extraction, namely Lonmin, the Société équatoriale d'exploitation forestière (SEEF) and Rougier.

\section{Institutional partners}

The main institutional partners working in the MA-MC landscape are:

- Conservation and Rational Use of Forest Ecosystems in Central Africa (ECOFAC)

- Wildlife Conservation Society (WCS)

- World Wide Fund for Nature (WWF)

- International Union for the Conservation of Nature/Central African Regional Program for the Environment (IUCN/ (ARPE)

- Missouri Botanical Garden (MBG)

- INDEFOR: Instituto Nacional de Desarrollo Forestal y Gestión del Sistema de Áreas Protegidas (National Institute for Forest Development and Management of the Protected Areas System in Equatorial Guinea)

- $\quad$ National biodiversity institute, Equatorial Guinea(IUBioma)

\section{Opportunities, adaptation and REDD+}

The following characteristics of the landscape are of relevance to adaptation and REDD+ activities.

- The low population density across the entire landscape, compared with other landscapes in the Congo Basin, means that pressure on forests and resources, whether forest or other natural resources, is relatively low, thus reducing potential leakages in REDD+ projects.

- Existing laws and regulations in both countries, if enforced, can facilitate adaptation and REDD+ activities.

- Spatial and land use plans have been made for all the protected areas in the landscape, and could result in a net reduction of deforestation if they were fully implemented.

- $\quad$ Projects aimed at diversifying subsistence options, such as horticulture and goat and pig rearing, are improving the adaptive capacity of people who are experiencing reduced access or difficulty in gaining access to natural and forest resources.

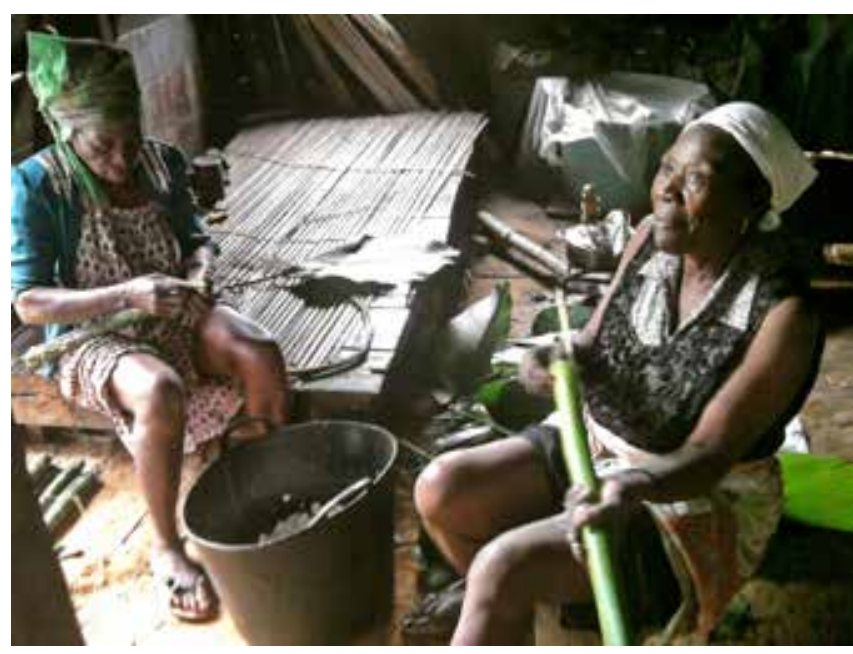

Cassava processing

\section{Challenges, constraints for REDD+ and adaptation}

Following are the main threats to the MA-MC landscape.

- Local people have little involvement in landscape management and conservation, particularly in protected areas, making it difficult to engage them in communitybased adaptation and mitigation activities based on natural resources management.

- Multiple organisations and projects are operating in the landscape on an individual basis. A major challenge is to coordinate various activities and organisations effectively, in order to achieve synergistic results and consistent interventions, and hence improve adaptive capacity.

- A cause of conflict is the lack of clear and fixed national borders in the MA-MC landscape. Having clear borders between the two countries will help avoid misunderstandings and lead to better management of the landscape and its reserves and parks.

- Local people's lack of awareness of existing laws and regulations and companies' failure to comply with these laws lead to abusive exploitation of resources, by both groups, thus hampering the success of adaptation and mitigation interventions.

\section{Documents consulted}

Devers, D. and J.P. Vande weghe (eds). 2007. The forests of the Congo Basin - state of the forest 2006. Publications Office of the European Union, Luxembourg.

de Wasseige, C. and D. Devers (eds). 2009. The forests of the Congo Basin - state of the forest 2008. Publications Office of the European Union, Luxembourg.

de Wasseige, C. and D. Devers (eds). 2011. The forests of the Congo Basin - state of the forest 2010. Publications Office of the European Union, Luxembourg. 
Ministry of Fisheries and the Environment of Equatorial Guinea. 2009. Informe nacional sobre le diversidad biologica. March 2009.

Ko, J. 2011. Rapport annuel 2012: Activités USAID/CARPE dans les paysages COMIFAC/PFBC à l'appui du plan de convergence de la COMIFAC (Septembre 2009-Septembre 2010)

UNESCO and COMIFAC. 2008. Patrimoine mondial naturel d'Afrique Centrale: biens existants, biens potentiels. Report from a workshop, Brazzaville, 12-14 March.
UNEP/CMAS. 2008. Accord sur la conservation des gorilles et de leurs habitats. http://www.cms.int/species/gorillas/mop1/action_plan_ggg_west_f.pdf (20 September 2012)

National Agency for National Parks (Gabon). 2011. Le Parc National des Monts de Cristal. http://www.parcsgabon.org/decouvrez-les-parcs/les-13-parcsnationaux/parc-national-des-monts-de-cristal (20 September 2012)
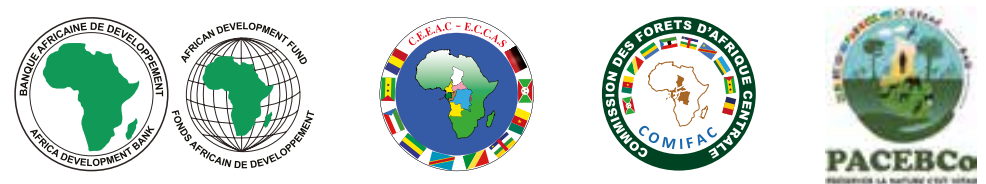

cifor.org/cobam

blog.cifor.org

\section{Center for International Forestry Research}

CIFOR advances human wellbeing, environmental conservation and equity by conducting research to inform policies and practices that affect forests in developing countries. CIFOR is a CGIAR Consortium Research Center. CIFOR's headquarters are in Bogor, Indonesia. It also has offices in Asia, Africa and South America. 